\title{
EXTRAFASCIAL PNEUMOTHORAX
}

\author{
BY \\ MICHA KONSTAM \\ Surrey County Sanatorium, Milford
}

In the treatment of pulmonary tuberculosis by thoracoplasty combined with Semb apicolysis, circumstances often arise which make it desirable to maintain over a prolonged period the relaxation obtained after the first-stage operation. This is mainly the case when subsequent stages have to be delayed on account of a spread to the same or to the opposite lung, or when a pleural effusion, intercurrent illness, or general debility are present. By keeping the lung apex and the attached periosteum down at the level to which apicolysis has lowered it, the benefits of the first stage should be retained.

Since 1935 we have experimented at Milford Sanatorium with the artificial maintenance of the Semb space, and we have attempted it in thirtyone patients. The indications were at first confined to cases in which complications had arisen, delaying further operations. Later, as experience taught us that a good proportion of patients with apical cavities not larger than about $2 \mathrm{~cm}$. in diameter could be successfully treated by a three-rib thoracoplasty combined with temporary extrafascial collapse, the indications for the artificial maintenance of the Semb space were extended to patients with limited apical disease and small cavitation.

Three substances, saline, air, or olive oil, have been used to keep the Semb space open, and all are effective. Air seemed preferable to saline because there was less risk of secondary infection, and olive oil was tried in order to obviate the tedium of frequent refills. The time at which refills are started is important. In order to lose none of the original Semb space, it is advisable to begin refills as early as possible after the operation, but it is essential to wait until firm union of the sutured muscles has occurred. The optimum time is in the second postoperative week. A useful precaution is to leave the skin sutures in for at least a fortnight if refills are begun before this time.

All recent cases have been treated initially by insufflations of air, and the procedure for this will be described. The safest approach is from behind, with the patient lying prone. A needle, connected with a two-way stopcock and syringe, is inserted just lateral to the second transverse process, avoiding the stitch holes and directed ventrally and caudally. The needle must be long enough to transverse the fat, muscle, and postoperative oedema; three inches is the minimum length required. When the Semb space is entered, there is a sensation of "give," and either air, effusion, or both, may be aspirated. The stopcock is then connected to an artificial pneumothorax apparatus and a small quantity of air is injected, for example $100 \mathrm{c.cm}$., care being taken not to raise the pressures beyond mild positive readings of +5 to $+10 \mathrm{ml}$. of water in the early days. Refills are repeated on the next day and upon alternate days until the third postoperative week, when twice weekly refills are begun and air is introduced until high positive pressures $(+40 \mathrm{ml}$. of water) are obtained. A small respiratory swing of 1 or $2 \mathrm{~cm}$. will be observed. The posterior approach for refills is preferable to the anterior for the following reasons: it enables the physician to look out for a pneumocele during the insufflation; and there is less risk of lung puncture or of accidentally inducing an unwanted intrapleural pneumothorax below the thoracoplasty. Once a good size Semb-space pneumothorax has been established it is safe to refill from the front ; this is less troublesome to the patient.

Refills have been kept up until such times as the patient was fit to undergo subsequent thoracoplasty stages or for six months, after which it was thought that the regenerated ribs would keep the apex in the lowered position. In fact it was found that the slender regenerated ribs did not always suffice to keep the apex at the lower level, and a rise of 1 or $2 \mathrm{~cm}$. occurred after absorption of the air.

In favourable cases the Semb space effusion has been absorbed within about three to eight weeks. In six patients whose cavities have been controlled by a one-stage thoracoplasty of three ribs, we have substituted olive oil for the air after absorption of the effusion. With the patient lying prone and the needle inserted at the highest point of the 
Semb space, oil was injected, with pauses to allow the air to escape. No pressure was exerted, and a month later it was found that only a few $\mathrm{ml}$. of oil could be added without raising the pressures.

\section{RESULTS}

In this series of thirty-one cases, seven were unsuccessful. The failures were due in two patients to rupture of the wound, exposing a gaping Semb space ; in these the muscles and skin were re-sutured and the treatment abandoned. In a further two cases the muscle sutures gave way and a pneumocele appeared under the skin ; removal of the air saved the scar, but treatment by refills was abandoned. In two other patients treatment was begun in the third postoperative week and, as the original strip had been of moderate extent, a poor space was obtained. In one patient a good pneumothorax could not be established on account of massive clot. Three patients developed tuberculous effusions. Of these, two were in an extremely low state of health at the time of the operation, and the third had probably had the lung punctured. Clinically, the tuberculous Semb space infections were silent, and they were only detected at fluoroscopy. Treatment by repeated aspirations, aiming at obliteration of the space, was easily and successfully carried out. Tuberculous effusion is to be suspected if the original postoperative effusion fails to dry up or if an effusion appears during the course of treatment. Aspiration confirms the diagnosis, but the recognition of tuberculous infection may present difficulties in cases converted to oleothorax. General considerations suggest that tuberculous infection might manifest itself in increased pressure in the space and that pressures should be taken occasionally in the oleothorax cases. Radiological observation of oil above a sero-sanguinous effusion sometimes shows that the effusion casts a denser shadow than the oil, but this difference is not always clearly discernible. One patient developed the signs and symptoms of a mild air embolus. Surgical emphysema can occur but is not important.

In the remaining patients in whom a Semb space pneumothorax was established or in whom refills of liquid were given, the results have been the maintenance of the original collapse. When the space was allowed to obliterate, only very slight re-expansion of the apex occurred, as compared with the re-expansion which occurs in similar cases in which no special measures have been taken to maintain the space. The second and third stages of thoracoplasty were safely delayed for many weeks and up to three months without loss of the benefit of the previous operations, and in a series of nine patients with upper-zone cavities not larger than $2 \mathrm{~cm}$. in diameter it was possible to obtain control of the disease and cavity closure by a one-stage three-rib thoracoplasty followed by Semb space pneumothorax.

\section{SUMMARY}

A method is presented which enables the second and subsequent stages of a Semb thoracoplasty with apicolysis to be delayed if the patient's condition postoperatively warrants such a step. The Semb space is maintained by the introduction of saline, air, or oil, and the lung apex remains at its lowered level until rib regeneration occurs. Only one reference to this method has been found in the literature: Aycock and others (1940) described experiments to the same purpose, with good results.

A new observation, which may have far-reaching consequences in the surgical treatment of pulmonary tuberculosis and which may widen its scope, is recorded, namely that certain small apical cavities can be controlled by the removal of three ribs followed by apicolysis and refills of the operation space. The successful use of the one-stage three-rib upper thoracoplasty with artificial maintenance of the Semb space has these principal advantages: the thoracoplasty is more selective and impairs the vital capacity considerably less than the conventional methods, and bilateral treatment could be applied in many more cases than are deemed suitable at present; the deformity caused by the sinking forward of the scapula which follows the more extensive thoracoplasty is obviated.

I am indebted to Dr. R. J. Allison for permission to publish these cases, to Mr. N. R. Barrett for first encouraging these experiments, and to Mr. W. P. Cleland for many helpful suggestions and much guidance.

\section{REFERENCE}

Aycock, T. B., Brantigan, O. C., and Welch, H. (1940). J. thorac. Surg., 9, 382. 


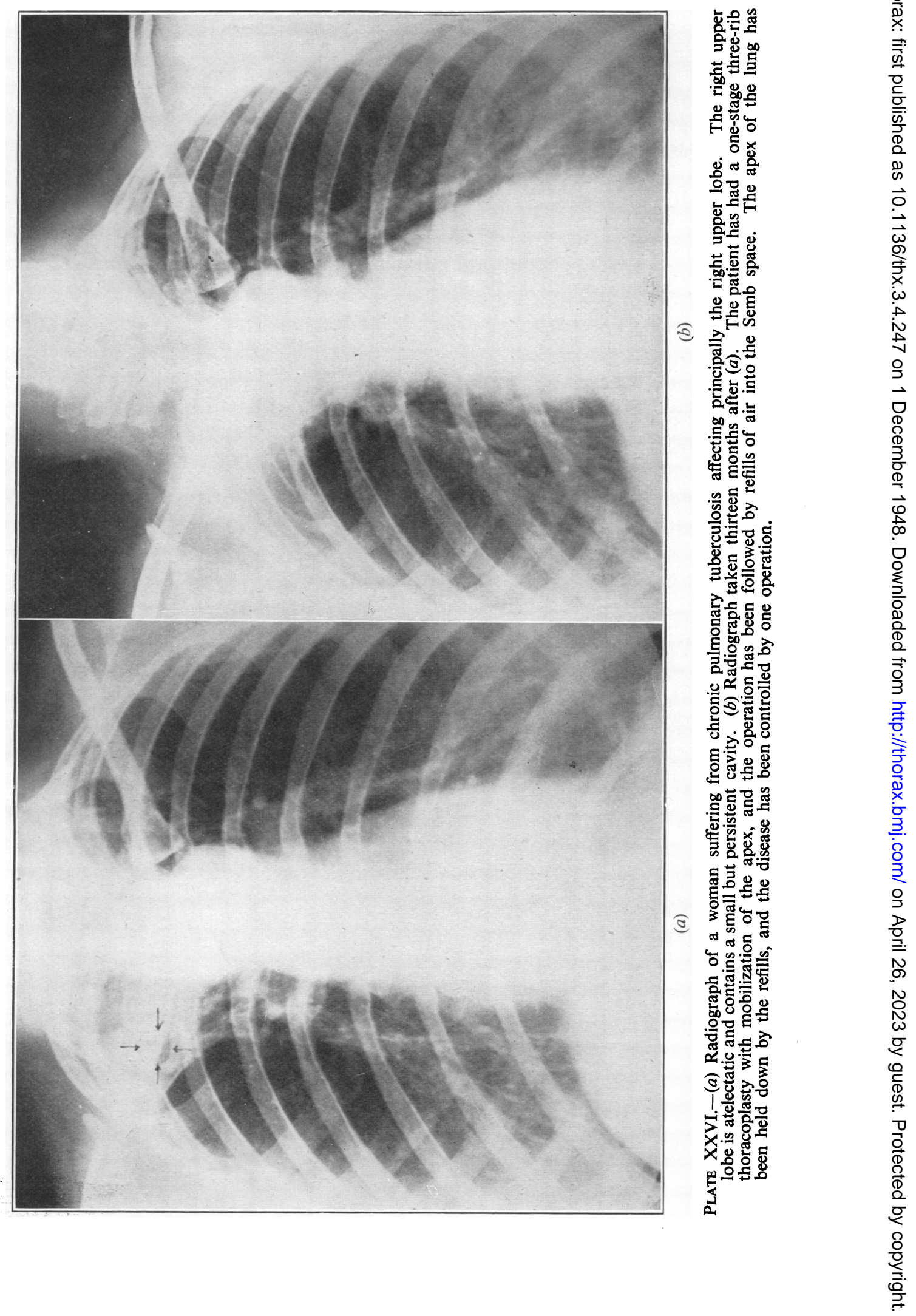


(a)

Plate XXVII.-(a) Radiograph showing extensive phthisis at the left apex with cavitation: at the left base there is some diffuse mottling, and the heart is slightly displaced to this side. At the right apex there is old-standing disease. The patient was sputum-positive. (b) Radiograph of the same patient as in (a) but taken after an upper-stage thoracoplasty with mobilization of the apex of the lung. Refills of the space created by the operation are being given at this time, and the film shows that the lung is being held well down. There is no effusion in the space. (c) Radiograph of the same patient as in $(a)$ and $(b)$ but taken two months after $(b)$. The air has been replaced by olive oil. The apex of the lung is held well down at the level to which it was displaced at operation.

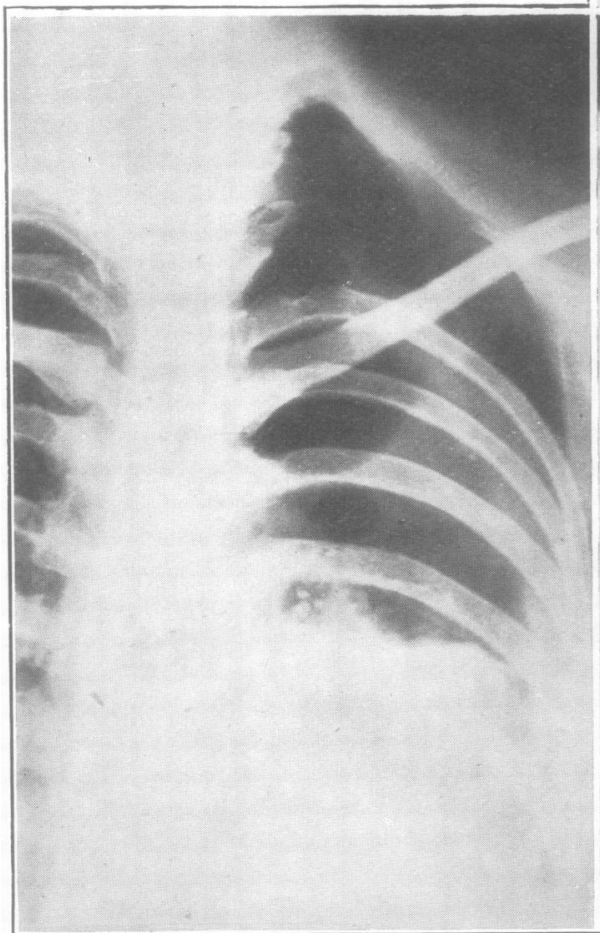

(b)
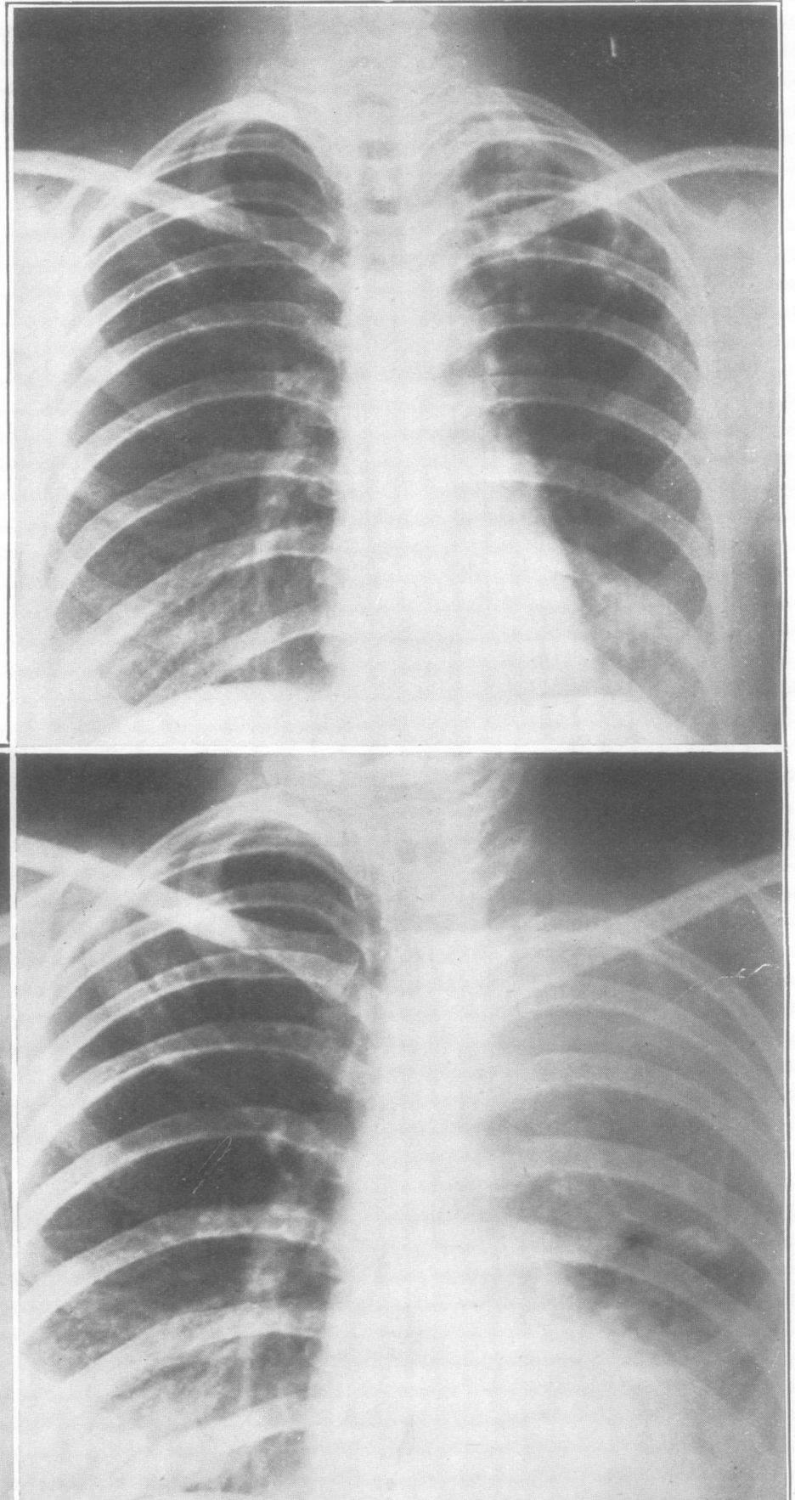

(c) 